\title{
IOP APP, (Physiology \\ LUNG FUNCTIONS IN STUDENTS UNDERGOING GYM TRAINING AND SEDENTARY MEDICAL STUDENTS - A COMPARATIVE STUDY
}

\section{Dr Taruna*}

Dr Anju Goel
Assistant Professor, Department of Physiology, Rama Medical college, Hapur, UP, India. *Corresponding Author

Associate Professor of Physiology Department, Rama Medical college, Hapur, UP, India

Dr Manisha Gupta Professor \& Head of Physiology Department, Rama Medical college, Hapur, UP, India

\section{Dr Namrata Kar}

Professor of Physiology Department, Rama Medical college, Hapur, UP, India

ABSTRACT Constant and consistent exercise improves the efficiency of our lungs, and everyone, especially young adults, need to work on this organ along with the rest of their body for a healthier life. Hence the present pilot study was undertaken to show that consistent GYM training would exhibit a significantly greater lung capacity.

Aim: To compare the lung functions in students undergoing gym training and sedentary students.

Material and Methods: This Pilot study was conducted in 40 healthy male medical students in the age group of 20 to $30 \mathrm{yrs}$. The recruited students were divided into two groups - Group1 with Gym training and Group2 Sedentary students. Both the groups were age and BMI matched in order to minimize the confounding factors and make the study reproducible. Lung functions of both the groups were assessed by a computerized RMS Spirometer Helios 401. Unpaired t - test was used for statistical analysis.

Results: The study revealed that the Mean \% FEV1 of Group1 (4.28) was significantly higher as compared to Group 2 subjects (3.30) Mean percent of FEV1 /FVC also had a higher value for Gym group (94.41) than sedentary group (87.36). Mean \% FEF (25 - 75) was 5.57 and PEFR was 8.96 in Group1 as compared to 4.33 and 6.30 in Group2 respectively. FVC did not show significant change.

Conclusion: We concluded that a physically active lifestyle improves the lung functions and delays its decline. Therefore, it's imperative that the younger generation should incorporate some form of regular exercise regimen in their lifestyle for their physical and mental wellbeing.

\section{KEYWORDS : Gym training, Healthy lifestyle, Lung functions}

\section{INTRODUCTION}

Students nowadays lead a sedentary lifestyle due to long study hours and spend most of their time sitting and accessing digital media. This is taking a toll on their health and decreasing their endurance. It is well known that such a lifestyle is a predisposing factor for cardiovascular diseases, diabetes, obesity, high blood pressure, osteoporosis, lipid disorders, depression and anxiety. Azad et al. (2011) noted that young subjects with sedentary lifestyle are at a higher risk for deterioration of their respiratory indices and may be at risk for developing chronic obstructive pulmonary disease in adulthood .He also reported a positive correlation between physical activity, physical fitness, and lung capacity [1]. Physical exercise has many positive effects on respiratory system functioning as it improves aerobic strength and reduces shortness of breath while also improving VO2max, an indication of harmony between the cardiovascular and respiratory systems $[2,3]$. Regular physical activity suppresses the production of inflammatory markers such as Interleukin-6 (IL-6), Tumor Necrosis Factor-Alpha (TNF-a), and C-Reactive Protein (CRP)[4].

Exercise improves the endurance and strength of the respiratory muscles of athletes, decreases resistance in the respiratory tract, and increases lung elasticity and alveolar expansion by promoting the expansion of pulmonary volumes and capacities [5]

Extensive research has shown that regular aerobic exercises constitute a way to increase inspiratory muscle function and elastic recoil of the lungs, but there still exists paucity of scientific documentation relating to the effect of gym exercises, mainly isotonic, on lung functions. Few studies have established that in addition to upper body resistance exercises, breathing exercises are capable of increasing the pulmonary ventilation and improving mobilization of the chest wall, drainage of trachea bronchial secretions, promote relaxation, which contributes to a significant increase in vital capacity (VC), FEV1, peak expiratory flow (PEF), and maximal voluntary ventilation (MVV).[6]

Through this study we aimed to investigate whether the students who are following a regular exercise regime (Gym exercises in present study) have better lung functions as compared to non-exercising students, so that such students can be sensitized to pursue a healthy lifestyle.

\section{MATERIALAND METHODS}

A total of 40, age and BMI matched healthy, male medical students were recruited in the study, which was conducted in the research lab of the Physiology department, Rama Medical College, Hapur.

All subjects with any clinical history of respiratory or cardiovascular disease were excluded from the study. The experimental protocol was explained to the subjects and informed consent was taken. They were asked to avoid beverages, like tea and coffee and other stimulants and come with light breakfast before reporting. The study was approved by an institutional ethical committee.

Subjects were divided in two groups

Group $1(\mathrm{n}=20)$ - Students with Gym training

Group 2( $n=20)$ - Sedentary students.

The Group 1 subjects were following a regular workout regimen of 60 min. exercises like bench press, arm extension, leg press, abdominal crunches and squats for at least 5 days a week for the last 3 months. Group 2 subjects were not doing any type of exercise on a regular basis.

Height and weight of students was recorded, and BMI calculated using the Quetelet's index: BMI=Weight $(\mathrm{kg}) /$ Height2 $(\mathrm{m})$.

Recording of lung functions was carried out on a computerized Spirometer- RMS Helios 401. The parameters chosen were-

1. Forced vital capacity (FVC)

2. Forced expiratory volume in $1^{\text {st }}$ second (FEV1)

3. Peak expiratory flow rate (PEFR)

4. Percentage of FEV1/FVC ratio

5. Forced expiratory Flow during $25-75 \%$ of Expiration (FEF $25-$ $75 \%)$

The subjects were instructed to give maximum co-operation during the study. They were asked to take maximum inspiration and then blow into the spirometer as rapidly, forcefully and completely as possible for a minimum of $6 \mathrm{sec}$. followed by full and rapid inspiration to complete the flow volume loop. The nose clip was applied during the procedure. The best of the 3 trials was considered for data analysis.

\section{Data Analysis}

Data was entered in Microsoft Excel and analyzed using the SPSS version 20 Unpaired ' $t$ ' test was used for statistical analysis. P value $<0.05$ is considered as significant. 


\section{OBSERVATIONS AND RESULT}

The study which included 40 normal healthy MBBS students divided into two groups (20 Gym training students \& 20 Sedentary group). The mean age and mean anthropometric measurements of both groups (Table 1) suggest that both the groups did not differ significantly and hence they are comparable.

\section{Table1}

\begin{tabular}{|c|c|c|c|c|c|}
\hline \multirow{2}{*}{ Variable } & \multicolumn{2}{|c|}{ Group 1 } & \multicolumn{2}{c|}{ Group 2 } & \multirow{2}{*}{ P-value } \\
\cline { 2 - 5 } & Mean & SD & Mean & SD & \\
\hline Age & 22.57 & 3.82 & 22.79 & 2.99 & 0.8408 \\
\hline Weight (Kg) & 78.21 & 11.50 & 72.43 & 10.61 & 0.1068 \\
\hline Height (cm) & 176.43 & 8.05 & 174.36 & 6.69 & 0.3820 \\
\hline
\end{tabular}

The groups have been analyzed for various parameters and values for all measurements are expressed as mean $\pm \mathrm{SD}$ (Table 2$)$.

Mean \% FEV1 of Gym training group (4.28) is statistically significant as compared to Sedentary group (3.30)

Mean percent of FEV1 /FVC also has a higher value for Gym group (94.41) than sedentary group (87.36) so statistically it is significant

Table2

\begin{tabular}{|c|r|c|c|c|c|}
\hline \multirow{2}{*}{ Variable } & \multicolumn{2}{|c|}{ Group 1 } & \multicolumn{2}{c|}{ Group 2 } & \multirow{2}{*}{ P-value } \\
\cline { 2 - 5 } & Mean & SD & Mean & SD & \\
\hline FVC & 4.48 & 0.83 & 4.08 & 0.54 & 0.0788 \\
\hline FEV1 & 4.28 & 0.64 & 3.30 & 1.01 & $0.0008^{*}$ \\
\hline FEV1/FVC \% & 94.41 & 6.93 & 87.36 & 5.73 & $0.0012^{*}$ \\
\hline FEF (25-75) \% & 5.57 & 1.15 & 4.33 & 0.78 & $0.0003^{*}$ \\
\hline P E F R & 8.96 & 1.71 & 6.30 & 1.73 & $<0.0001^{*}$ \\
\hline
\end{tabular}

Mean \% FEF (25 - 75) is also higher in the Gym Group (5.57) than Sedentary group (4.33) which is statistically significant.

The mean PEFR (L/s) in Gym group (8.96) as compared to Sedentary group (6.30) had a p value of less than 0.0001 showed statistically significant difference.

But $p$ value of FVC (L)is more than 0.05 so by unpaired 't test' is not significant

These findings show a better Lung function results in group doing gym workout as compared to sedentary group.

\section{DISCUSSION}

The result of this study supports the previous works done by Rajendra Atmaram et al which revealed that pulmonary functions of healthy individuals who regularly did gym workout for 1 hour for 5 days a week for at least 3 months improved. Better lung volumes, capacities and flow rates were achieved at the end of 3 months of workout period. [7]

Narayan Bahadur and Lava Shrest also found that athletes who did strenuous respiratory muscle exercise like swimming and weight lifting had better pulmonary function tests (PFTs) compared to other athletes like sprinters [8] Similar results were reported by Tijana Durmic et al who also suggested that the type of sport has a significant impact on respiratory adaptation. [9]

The Physiological basis of improved pulmonary function can be due to reasons like decreased airway resistance, increased airway caliber, strengthened principal and accessory respiratory muscles, increased lung and thoracic elasticity etc. All these factors may be responsible for improved PEFR, FVC and FEV1. Activation of adrenaline system during exercise training in which vasodilation of pulmonary vessels caused a decreased airway resistance and an enhanced FVC and FEV1 through increasing airflow. Also, regular forceful inspiration and expiration during exercise leads to strengthening of the respiratory muscles which in turn help the lungs to inflate and deflate maximally. This maximum inflation and deflation is an important physiological stimulus for the release of surfactant as stated by Hildebrean and et al [10].

Our study also supports the previous studies which stated that regular long-term physical exercises help improve the strength of respiratory muscles [11], while good physical fitness is associated with better respiratory function [12]. Therefore, participation in certain physical activities or sports may lead to the strengthening of respiratory muscles, improvements in pulmonary functions, and achieving an effective pulmonary function (FVC, FEV1) $[13,14]$

However, our study did not find significant statistical change in $\mathrm{FVC}$ as reported by Arwa Rawashdeh, et al [15] who also found no improvement in FVC after exercise. The increase in FVC value seen by Shobha Rani Vedala et al [16] can be due to longer duration of exercise training and larger sample size. Further the results of spirometry may show variability as they are dependent on the patient's efforts and consistency. Thus, in order to reach an effective level of FVC, people may have difficulty compared to producing FEV1.

Though it is evident from this pilot study that regular Gym training improves the pulmonary functions, a detailed and comprehensive study with larger sample is needed to provide a better insight.

\section{CONCLUSION}

The study revealed that the sedentary subject's performance on PFT was poorer when compared with subjects doing Gym training. This emphasizes the need to change their lifestyle and adopt measures like exercises for better pulmonary function and for better health.

The results of this study could be used for the selection of better sportsmen and in recruitment of army and police personnel as well as in the services where there is a need for better physical health.

\section{REFERENCES:}

1. Azad A, Gharakhanlou R, Niknam A \& Ghanbari A (2011). Effects of Aerobic Exercise on Lung Function in Overweight and Obese Students. Tanaffos 10(3), 24-31.

2. Doijad, V.P., Kample, P., Surdi, A.D. (2013). Effect of yogic exercises on aerobic capacity (VO2 max). International Journal of Recent Trends in Science and Technology, 6(3), 119-121

3. Fatima, S.S., Rehman, R., Saifullah Khan, Y. (2013). Physical activity and its effect on forced expiratory volume. Journal of Pakistan Medical Association, 63(3), 310-312

4. Garcia-Aymerich, J., Lange, P., Benet, M., Schnohr, P., \& Antó, J. M. (2007). Regular physical activity modifies smoking-related lung function decline and reduces risk of chronic obstructive pulmonary disease. American Journal of Respiratory and Critical Care Medicine, 175(5), 458-463.

5. Leith DE, Bradley M. Ventilatory muscle strength and endurance training. Journal of Applied Physiology.(1976);41:508-516.

6. El-batanouny MM, Amin Abdou M, Salem EY, El-Nahas HE. Effect of exercise on ventilatory function in welders. (2009) Egyptian Journal of Bronchology, 3:67-73.

7. Amin ,R., Shah,\& R. (2020). Effects Of Gym Workout On Pulmonary Function Tests In Healthy Adults. National Journal of Integrated Research in Medicine,11(4),19-21 http://nicpd.ac.in/ojs-/index.php/njirm/article/view/2853

8. Mahotra, N. B., \& Shrestha, L. (2013). Effects of type sports on pulmonary function tests: A comparative study in Nepalese settings. Journal of Nobel Medical College, 2(1), 18-21. https://doi.org/10.3126/jonmc.v2i1.7667

9. Durmic, T., Lazovic, B., Djelic, M., Lazic, J. S., Zikic, D., Zugic, V., Dekleva, M., \& Mazic, S. (2015). Sport-specific influences on respiratory patterns in elite athletes. Jornal Brasileiro de Pneumologia, 41(6), 516-522. https://doi.org/10.1590/s18063756201500000005

10. Hildebran, J. N., Goerke, J., \& Clements, J. A. (1981). Surfactant release in excised rat lung is stimulated by air inflation. Journal of Applied Physiology, 51(4), 905-910. https://doi.org/10.1152/jappl.1981.51.4.905

11. Akhade, V., \& Muniyappanavar, N. (2014). The effect of running training on pulmonary function tests. National Journal of Physiology, Pharmacy and Pharmacology, 4(2), 168. https://doi.org/10.5455/njppp.2014.4.151220131

12. Pelkonen, M., Notkola, I., Lakka, T., Tukiainen, H. O., Kivinen, P., \& Nissinen, A. (2003). Delaying decline in pulmonary function with physical activity. American (2003). Delaying decline in pulmonary function with physical activity. American
Journal of Respiratory and Critical Care Medicine, 168(4), 494-499. https:// doi.org/ Journal of Respiratory and Critic
$10.1164 /$ rccm.200208-954oc

13. Prakash, S., Meshram, S., Ramtekkar, U. (2007). Athletes, yogis and individuals with sedentary lifestyles. Do their lung functions differ? Indian J Physiol Pharmacol, 51(1),76-80.https://pubmed.ncbi.nlm.nih.gov/17877296/

14. Mahotra, N. B., Amatya, T. M., Rana, B. S., \& Banstola, D. (2017). undefined. Journal of Chitwan Medical College, 6(1), 21-23. https://doi.org/10.3126/jcmc.v6i1.16575

15. Rawashdeh, A., \& Alnawaiseh, N. (2018). The effect of high-intensity aerobic exercise on the pulmonary function among inactive male individuals. Biomedical and Pharmacology Journal, 11(2), 735-741. https://doi.org/10.13005/bpj/1427

16. Vedala, S., Paul, N., \& Mane, A. (2013). Difference in pulmonary function test among the athletic and sedentary population. National Journal of Physiology, Pharmacy and Pharmacology, 3(2), 118. https://doi.org/10.5455/njppp.2013.3.109-114 